\title{
Hofstede's Cultural Dimensions and Tourist Behaviors: A Review and Conceptual Framework*
}

\section{Las dimensiones culturales y la conducta turística según Hofstede: análisis y marco conceptual}

\author{
Lalita A. Manrai ${ }^{1}$ \\ Ajay K. Manrai
}

Received: January 14, 2011

Accepted: September 18, 2011

\begin{abstract}
This paper develops a conceptual framework for analyzing tourist behaviors and identifies three categories of behaviors based on the applications of Hofstede's cultural dimensions and the processes underlying these influences. Our findings indicate that tourist behaviors in the Before-Travel, During-Travel, and After-Travel stages differ significantly in terms of the applicability and process through which Hofstede's cultural dimensions operate. The results of our analysis suggest three categories of behavioral patterns, namely, "Social Interaction Driven Travel Behaviors," (SID), "Risk Tendencies Driven Travel Behaviors," (RTD), and "Collectivity Orientation Driven Travel Behaviors," (COD). SID relates to the evaluation of travel experiences in the after-travel stage. The dominant cultural values associated with SID are Individualism/Collectivism, Masculinity/Femininity, and Power Distance. These three values act either independently or in pairs or all three together. RTD relates to the consumption of travel products in the during-travel stage, and COD relates to the formation of travel preferences in the before-travel stage. Individualism/Collectivism and Uncertainty Avoidance are associated with both RTD and COD. However, the underlying processes differ for these two categories of travel behaviors. In addition to their independent influences on travel behaviors, these two values associated with RTD and COD also have an interactive effect. For RTD, the Uncertainty Avoidance motive determines the Individualism/Collectivism outcome, whereas, for COD, the opposite is true: the Individualism/Collectivism determines the Uncertainty Avoidance outcome. The paper also discusses the application of a fifth cultural dimension, Confucian Dynamism (short-term versus long-term orientation), for the study of tourists' behaviors.
\end{abstract}

Keywords: Hofstede's cultural dimensions, tourist behaviors, traveller's behaviors, Confucian Dynamism.

* The authors would like to dedicate this paper to Dr. Geert Hofstede whose work inspired this research. We would also like to acknowledge the valuable comments of the two anonymous reviewers and the journal editor in finalizing this manuscript.

1. Dr. Ajay K. Manrai and Dr. Lalita A. Manrai are both Professors of Marketing in the Department of Business Administration at the University of Delaware, Newark. <manrai@udel.edu>. 


\section{Resumen}

En este artículo se desarrolla un marco conceptual de análisis de patrones de conducta del turista e identifica tres categorías de conducta basadas en las aplicaciones de dimensiones culturales de Hofstede y los procesos subyacentes de estas influencias. Nuestros resultados indican que las conductas del turista en los estadios de Antes-del-viaje, Durante-el-viaje y Después-del-viaje difieren significativamente en términos de la aplicabilidad y el procesos a través de los cuales las dimensiones culturales de Hofstede operan. El resultado de nuestro análisis sugiere tres categorías de patrones de conducta, a saber, "Conductas de Viaje Dirigidas a Interacción Social" (SID por sus siglas en inglés), "Conductas de Viaje Dirigidas a Tendencias de Riesgo" (RTD por sus siglas en inglés), y "Conductas de Viaje Dirigidas a la Orientación Colectiva" (COD por sus siglas en inglés). SID se relaciona con la evaluación de las experiencias de viaje en la fase posterior al viaje. Los valores culturales dominantes asociados con SID son Individualismo-Colectivismo, Masculinidad-Feminidad, y Distancia del Poder. Cada uno de estos tres valores actúa independientemente, en pareja o los tres a la vez. RTD se relaciona con el consumo de productos de viaje en la fase de la travesía en sí, y COD se relaciona con la formación de las preferencias de viaje en la fase previa al viaje. Las categorías Individualismo-Colectivismo e Incertidumbre-Prevención están asociadas tanto con RTD como con COD. Sin embargo, los procesos subyacentes difieren de estas dos categorías de conductas de viaje. Además de las influencias independientes de conductas de viaje, estos dos valores asociados con RTD y COD también ejercen efectos interactivos. Para RTD, la motivación Incertidumbre-Prevención determina el resultado de IndividualismoColectivismo, mientras que para COD sucede lo contrario; es decir, el motivo Individualismo-Colectivismo determina el resultado de Incertidumbre-Prevención. El artículo también argumenta la aplicación de una quinta dimensión cultural, Dinamismo Confuciano (orientación a corto plazo frente a orientación a largo plazo) del estudio de las conductas de los turistas.

Palabras claves: Dimensiones culturales de Hofstede, conductas del turista, conductas del viajero, Dinamismo Confuciano. 


\section{INTRODUCTION}

The subject of cross-cultural differences in consumer behavior has been the focus of numerous research studies in the field of marketing (Beatty, Lynn, \& Pamela,1991; Mooij \& Hofstede, 2011; Manrai \& Manrai, 1996, 2011; Plummer, 1977; Watkins \& Lin, 1996). The marketing and the consumer behavior textbooks (Kotler \& Keller, 2009; Schiffman \& Kanuk, 2007) widely discuss the implications of culture on different aspects of consumer behavior such as consumer decision making, purchase and consumption related behaviors, consumer satisfaction, dissatisfaction, complaining behavior, etc. The influence of cultures on consumer behavior is evident in all areas of services, especially in the fields of travel and tourism. This is so because in today's global economy there has been an unprecedented growth in overseas travel making tourism truly a cross-cultural phenomenon.

Travel and tourism, however, is an extremely complex product for several reasons. First, it relates to goods and tangible products (souvenirs, gifts, food etc.) as well as intangible services (sightseeing tours, cultural performances, etc.). Second, the tourism product consists of a multitude of these goods and services put together and, in turn, there exists a multitude of options to choose from within each of the tangible goods and intangible service categories. Third, tourist decision making and behavior are influenced by several factors. Kotler and Keller (2009) present a model in which consumer behavior is portrayed to result from the cultural, social and personal characteristics of consumers as well as the consumer psychology. Models of cross-cultural consumer behavior developed by Manrai and Manrai (1996, 2011) conceptualize these four influences i.e.; cultural, social, personal, and psychological factors in a hierarchical, sequential and nested design with culture being the broadest influence. In their models, each of the four factors is depicted to have a direct as well as an indirect (through subsequent factors in the hierarchy) influence on consumer behavior.

While culture has been defined and classified in countless ways, researchers agree that cultural influ- ences transcend in terms of the beliefs, norms, traditions, and values of a society (Herkowitz, 1948; Hofstede, 1980, 2001; Kluckhohn, 1954; Triandis, 1994). The five cultural value dimensions identified by Hofstede $(1980,2001)$, namely, individualism versus collectivism, power distance, masculinity versus femininity, uncertainty avoidance, and Confucian dynamism (long versus short term orientation) have been widely acknowledged as the most significant approach to the study of cross-cultural differences in human behavior. Although originally identified in the context of a business setting, such as employee values, these five dimensions have been studied and proven relevant in a variety of other domains including consumer behavior and marketing, as well as travel and tourism research.

The objective of the research reported in this paper is to develop a conceptual framework analyzing the dominant cultural values and the processes underlying the influence of these values in various domains of tourist behaviors in the pre-travel, during-travel, and after-travel stages. Based on this analysis, three categories of tourist behaviors are identified. These three categories are labeled as Social Interaction Driven Travel Behavior (SID) in the post-travel stage, Risk Tendencies Driven Travel Behaviors (RTD) in the during-travel stage, and Collectivity Orientation Driven Travel Behaviors (COD) in the pre-travel stage as shown in Figure 1.

This paper is divided into seven sections. The next section summarizes the work of Hofstede and his colleagues related to the development of five cultural dimensions. The third section of the paper identifies a comprehensive list of tourist behavior domains in the three stages (pre, during, and post). Section four of the paper provides a literature review of the travel and tourism research applying the five cultural dimensions to the study of various domains of tourist behavior. In the fifth section of the paper, we analyze the patterns in the application of the five cultural dimensions to various tourist behavior domains and classify different tourist behaviors into three categories mentioned above that are SID, RTD, and COD. The sixth section of the paper discusses the managerial implications of our conceptual 


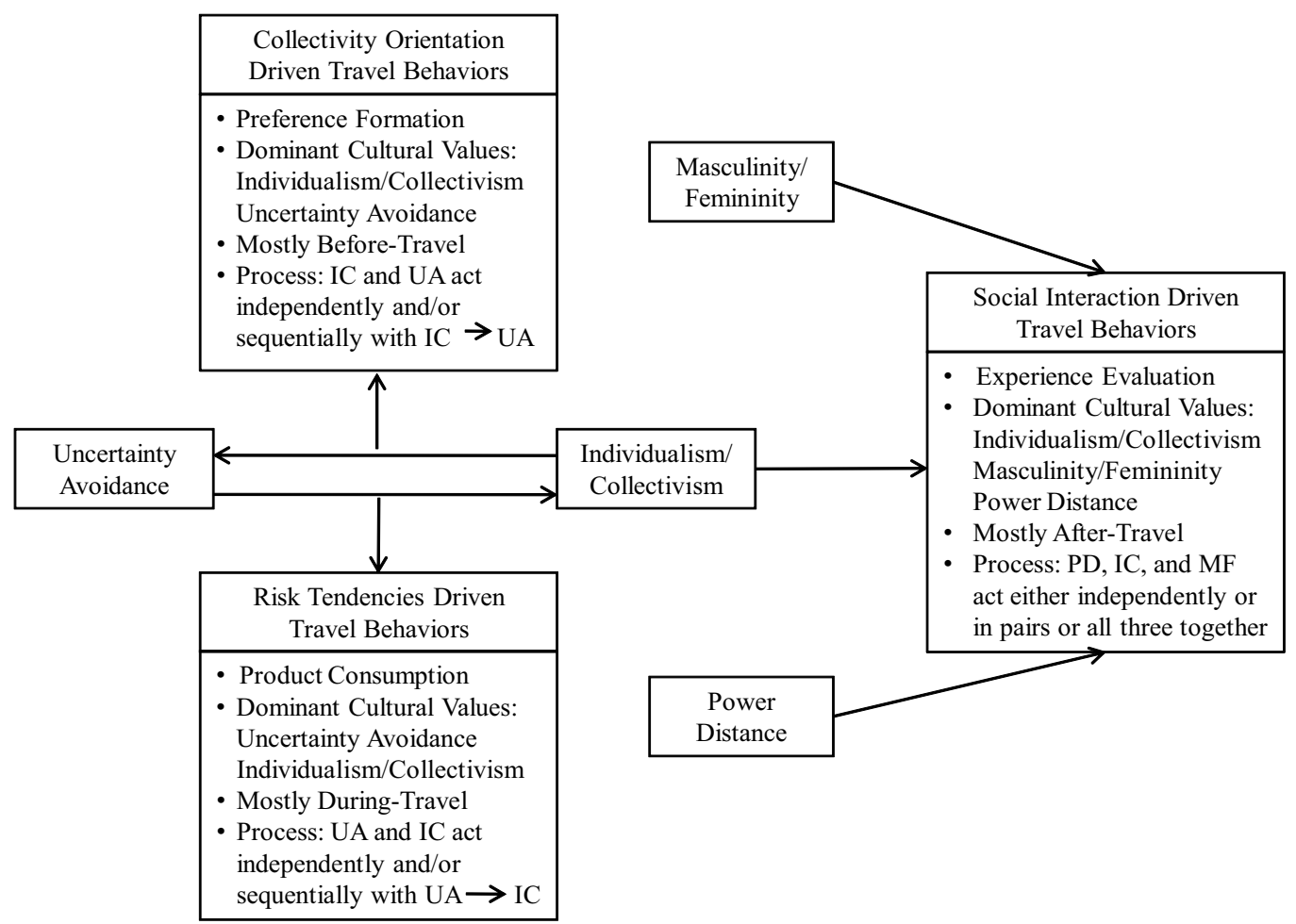

Figure 1. A Conceptual Framework for Analyzing Tourist Behaviors in the Before-, During-, and After- Travel Stages

framework and the final section identifies directions for future research.

\section{HOFSTEDE'S CULTURAL DIMENSIONS}

Geert Hofstede is the most well-known name in the field of cross-cultural psychology and business. He started in 1979 with 40 countries and in 1980 published his landmark study of work-related values of employees in 50 countries and three world regions (Hofstede 1979, 1980). The database for this unprecedented research study comprised of questionnaires completed by 100,000 employees of IBM, a large multinational corporation. Based on factor analysis of the data, Hofstede extracted four dimensions on which the different countries/ cultures varied. The validity of these four dimensions was tested using a variety of constructs and theories in social sciences.
Hofstede (1980) labeled these four dimensions as "Power Distance," "Uncertainty Avoidance," "Individualism versus Collectivism" and "Masculinity versus Femininity" respectively. He defined these four dimensions as follows:

\section{- Power Distance:}

The extent to which the less powerful members of institutions and organizations accept that power is distributed unequally.

\section{- Uncertainty Avoidance:}

The extent to which people feel threatened by ambiguous situations, and have created beliefs and institutions that try to avoid in such situations.

- Individualism versus Collectivism:

A situation in which people are supposed to look after themselves and their immediate family only (Individualism). 
A situation in which people belong to in-group or collectivities, which are supposed to look after them, in exchange for loyalty (Collectivism).

- Masculinity versus Femininity:

A situation in which the dominant values of society are success, money, and things (Masculinity).

A situation in which the dominant values of a society are caring for others and quality of life (Femininity).

Hofstede and Bond (1984) discuss the basic anthropological and societal issues to which the above four dimensions relate. These authors suggest that the power distance dimension is related to social inequality and the amount of authority of one person over others. The uncertainty avoidance dimension is considered related to the way a society deals with conflicts and aggressions and as the last resort with life and death. The third dimension, individualism versus collectivism, is portrayed as being related to the individual's dependence on the group; his or her self-concept as 'I' or 'We'. Lastly, the fourth dimension, masculinity versus femininity, is portrayed as being related to the choice of social sex roles and its effects on people's self-concepts.

Hofstede subsequently added a fifth cultural dimension, which he called "Confucian Dynamism" (referred in the literature also as "Long Term versus Short Term Orientation"). This fifth dimension was added because none of the original four cultural dimensions was related to national economic growth as demonstrated in case of several East Asian countries. A second cross-cultural value measurement project called "Chinese Values Survey (CVS)" was undertaken to identify values more typical to Asian cultures. CVS comprised of a 40-item questionnaire (Bond and the Chinese Cultural Connection 1987) on typical Chinese values and was administered in 22 countries, 20 of which overlapped with IBM study.

A comparison of the values identified in the two surveys, on IBM and CVS provided some very use- ful insights. The results of each of the two surveys exhibited four cultural dimensions but only three of them were similar: "Power Distance," "Individualism versus Collectivism," and "Masculinity versus Femininity." The cultural dimensions of "Uncertainty Avoidance" found in the IBM study was missing in CVS and instead the fourth dimension found in CVS study comprised of unique items associated with the thinking and philosophy of Confucius. Thus, this dimension was labeled as "Confucian Dynamism." Further, the Confucian values included in this dimension were both future or long-term oriented as well as present and past or short-term oriented. Therefore, this fifth dimension is also referred in the literature as long versus short term orientation.

Hofstede and Bond (1988) characterize the three dimensions common to both IBM and CVS studies as "Expected Social Behaviors." The "Power Distance" dimension captures behaviors toward juniors or seniors; the "Individualism versus Collectivism" dimension captures behavior toward the group and the "Masculinity versus Femininity" dimension captures behavior as a function of one's social sex roles. The dimension unique to the IBM study, "Uncertainty Avoidance", is portrayed as search for "truth," a typical Western value, whereas the dimension unique to the CVS study (Confucian Dynamism) is portrayed as the search for "virtue," a typical Eastern value (Hofstede \& Bond, 1988). The contrast of Eastern versus Western cultural values is very powerfully summed up by Hofstede and Bond (1988), where Confucius was a teacher of practical ethics, without any religious content. He dealt with Virtue but left the question of Truth open.

An overall examination of the cultural average scores and rankings of the various countries included in the IBM and CVS studies suggests that broadly speaking the Western countries tend to be low on power distance, low on uncertainty avoidance, high on individualism, mixed on masculinity - femininity and are short-term oriented. In comparison, Eastern countries tend to be high on power distance, high on uncertainty avoidance, high on collectivism, mixed on masculinity - femininity, and are long-term oriented. 


\section{TOURIST BEHAVIOR DOMAINS}

As discussed earlier in this paper, tourism is a complex global phenomenon involving a multitude of decisions related to the purchase and consumption of a variety of goods as well as services. Marketing textbooks (Kotler $\&$ Keller, 2009) identify five stages of decision making: 1) need recognition/purchase motives; 2) information search and information acquisition; 3) evaluation of alternatives, which involves rating of options and leads to formation of preferences and formation of behavioral intentions; 4) actual purchase and consumption decision, which involves purchase transaction related decisions (dealer choice, brand choice etc.), as well as consumption related decisions (frequency of purchase, light versus heavy users etc.); and 5) post-purchase behaviors such as consumer satisfaction/dissatisfaction, brand loyalty/brand switching, complaining/complementing behaviors, etc.

The above five stages of consumer decision making and related consumer behaviors are regrouped into three categories: 1) Before Purchase and Consumption; 2) During Purchase and Consumption; and, 3) After Purchase and Consumption. The "Before" category includes the first three stages of decision making listed above, which lead to the formation of preferences and behavioral intentions. The "During" category includes stage 4 and deals with product purchase and consumption related behaviors. The "After" category includes stage 5 and includes behaviors related to evaluations of the purchase and consumption experiences by the consumers. Parallel to this, the tourist behaviors are classified into three overall domains: 1) Before-Travel; 2) During-Travel; and, 3) After-Travel. Next, we identify several specific tourist behavior domains under each of these three overall groups. These domains are labeled BT1 to BT14 (for the Before-Travel group), DT1 to DT11 (for the During-Travel group) and AT1 to AT30 (for the After-Travel group). All these tourist behavior domains are listed in Table 1.

\section{Tourist Behavior Domains Before-Travel}

The first decision which a potential tourist is faced with is whether to travel or not, whether he/she can and/or should travel or not. There are various reasons for this dilemma. On the "No" side there may be personal, social, or financial constraints; there may be concerns related to the travel risk and safety, and, the individual may have travel anxiety etc. On the "yes" side, there is ample evidence documenting the benefits of travel and tourism. It fulfills a variety of personal, social, and recreational needs providing motives and incentives for travel. These needs may be triggered by a particular occasion, event or a life cycle stage. Overall, the prospective tourist has to carefully weight the advantages and disadvantages of undertaking the travel and tourism activity and take that very important first decision. We call this first decision "Yes-No to Travel" and label it as BT1. The Yes-No factors taken into account as discussed above are labeled as follows: On the "yes" side, Travel Benefits and Travel Motivations (BT2), Travel Occasion/Event/Life Cycle (BT3). On the "No" side, Travel Risk and Safety concerns and Travel Anxiety (BT4), Personal/Social/Financial constraints (BT5).

The assessment of the advantages and disadvantages of travel and tourism requires information search and acquisition. The process of information search and acquisition continues in case the individual has decided to undertake travel. Now he/she needs to search and collect information related to a variety of decisions such as what destination, what type of travel arrangements etc. There exits a multitude of sources from which the information can be acquired such as travel agents, internet, relatives and friends etc. The individuals also vary in terms of their need for planning and prior arrangements. While the information search and acquisition processes continue through the During-Travel stage, a substantial proportion of information search and acquisition activity takes place prior to travel. The above travel behaviors are labeled as follows: Information Search and Acquisition (BT6), Sources of Information (BT7), Trip Planning/Prior Arrangements (BT8).

Next, the individuals aggregate the collected information and evaluate their alternatives to form preferences. The evaluation process takes into account four main variables: 1) attributes used for evaluation 
Table 1.

Index of Tourist Behaviors in the Before-, During-, and After-Travel Categories

\begin{tabular}{|c|c|c|c|}
\hline Index \# & Tourist Behaviors & Index \# & Tourist Behaviors \\
\hline & BEFORE TRAVEL & & AFTER TRAVEL \\
\hline BT1 & Yes-No to Travel Decision & AT1 & Destination Service/Quality Evaluation \\
\hline BT2 & Travel Benefits/Travel Motivations & AT2 & Destination Price/Value Evaluation \\
\hline BT3 & Travel Occasion/Event/Travel Life Cycle & AT3 & Destination Overall Evaluation/Image \\
\hline BT4 & Travel Risk, Safety Concerns and Travel Anxiety & AT4 & Destination Overall Satisfaction \\
\hline BT5 & Personal, Social, Financial Constraints & AT5 & Destination Revisit Intention \\
\hline BT6 & Information Search and Acquisition & AT6 & Travel Mode Quality Evaluation \\
\hline BT7 & Sources of Information & AT7 & Travel Mode Price Evaluation \\
\hline BT8 & Trip Planning/Prior Arrangements & AT8 & Travel Mode Overall Evaluation \\
\hline BT9 & Travel Mode Preference & AT9 & Travel Mode Overall Satisfaction \\
\hline BT10 & Travel Destination Preference & AT10 & Travel Mode Repeat Purchase Intention \\
\hline BT11 & Transportation Preference & AT11 & Transportation Quality Evaluation \\
\hline BT12 & Accommodation Preference & AT12 & Transportation Price Evaluation \\
\hline BT13 & Food Preference & AT13 & Transportation Overall Evaluation \\
\hline \multirow[t]{3}{*}{ BT14 } & Activities at Destination Preference & AT14 & Transportation Overall Satisfaction \\
\hline & & AT15 & Transportation Repeat Purchase Intention \\
\hline & DURING TRAVEL & AT16 & Accommodation Quality Evaluation \\
\hline DT1 & Travel Mode Choice & AT17 & Accommodation Price Evaluation \\
\hline DT2 & Travel Destination Choice & AT18 & Accommodation Overall Evaluation \\
\hline DT3 & Transportation Choice & AT19 & Accommodation Overall Satisfaction \\
\hline DT4 & Accommodation Choice & AT20 & Accommodation Repeat Purchase Intention \\
\hline DT5 & Food Choice & AT21 & Food Quality Evaluation \\
\hline DT6 & Activities at Destination Choice & AT22 & Food Price Evaluation \\
\hline DT7 & Number of Destinations in Itinerary & AT23 & Food Overall Evaluation \\
\hline DT8 & Travel Party Size/Travel Companions & AT24 & Food Overall Satisfaction \\
\hline DT9 & Travel Frequency & AT25 & Food Repeat Purchase Intention \\
\hline DT10 & Trip Duration/Length of Stay & AT26 & Activities Quality Evaluation \\
\hline \multirow[t]{4}{*}{ DT11 } & Behavior on Group/Package Tours & AT27 & Activities Price Evaluation \\
\hline & & AT28 & Activities Overall Evaluation \\
\hline & & AT29 & Activities Overall Satisfaction \\
\hline & & AT30 & Activities Repeat Purchase Intention \\
\hline
\end{tabular}

of alternatives; 2) perceptions of alternatives on the key attributes; 3 ) importance weights the individuals attach to the different attributes; and, 4) method of aggregating the information on the above three variables to arrive at overall preferences. The key decision areas in this stage of preference formation relate to the travel mode (package/group versus independent/nonpackage), destination, transportation, accommodation, food, and activities. Considering the complexity of the tourism product, many tourists are either not able to or not willing to make their own arrangements and resort to taking package tours instead of making their own 
independent arrangements. On the other hand, many tourists are willing to deal with making their own arrangements for the sake of benefits they see and the capabilities they have to make these arrangements. Therefore, the research area of determinants of travel mode preference (package versus independent travel) is in itself an important area of tourist behavior research. In fact many tourists rely on their tour operators and travel agents for suggestions on destinations for consideration. We identify six more travel behaviors in the "Before-Travel" stage: 1) Travel Mode Preference (BT9); 2) Destination Preference (BT10); 3) Transportation Preference (BT11); 4) Accommodation Preference (BT12); 5) Food Preference (BT13); and, 5) Activities at Destination Preference (BT14).

\section{Tourist Behavior Domains During-Travel}

While the last set of travel behavior domains identified in the "Before-Travel" stage deals with the formation of preferences and behavioral intentions (BT9 to BT14), the travel behaviors discussed in this section deal with choices and behaviors related to purchase and consumption of travel products. The first set of During-Travel behaviors identified corresponding to these preferences (BT9 to BT14) describes the following choices: Travel Mode Choice (DT1), Destination Choice (DT2), Transportation Choice (DT3), Accommodation Choice (DT4), Food Choice (DT5), and Activities at Destination Choice (DT6).

Each of the above decision areas includes a variety of sub-decisions on which differences amongst tourists from different cultures can be expected. These differences capture the norms of various societies, individual differences or personal characteristics as well as the psychological processes underlying travel and tourism behavior. Also, these differences affect the characteristics of trips taken by tourists from different cultural backgrounds. In the current research, following trip characteristics are included for study: Number of Destinations in Itinerary (DT7), Travel Party Size/ Travel Companions (DT8), Travel Frequency (DT9), and Trip Duration/Length of Stay (DT10). The topic of Tourist Behavior on Group/Package Tours has also drawn a lot of attention in the travel and tourism research and is included as a separate travel domain in the during-travel stage (DT11) in the current study.

\section{Tourist Behavior Domains After-Travel}

This category of travel behaviors relates to the evaluations of different components of the tourism experience subsequent to the purchase and consumption of the tourism product. This tourism product is evaluated on various attributes/criteria. However, two attributes that are salient to the overall evaluations are quality and price. We, therefore, include these two variables separately in addition to the overall evaluations.

Tourist evaluations are followed by a variety of post-purchase and consumption processes. These processes include tourist satisfaction/dissatisfaction and intention to revisit/repurchase. The satisfaction is based on expectations, which tourists typically have in the "Before-Travel" stage, and perceived performance or evaluations, which result after the travel experiences in the "During-Travel" stage. When the perceived performance exceeds the expectations, it leads to satisfaction; on the other hand, when the perceived performance falls below the expectations, it leads to dissatisfaction. Typically, the satisfaction is positively related with the repeat visit or repeat purchase intention. Thus, for each of the six basic components of tourism experience (travel mode, destination, transportation, accommodation, food, and activities at destination) five measures of tourist behavior in the "After-Travel" stage are considered: 1) service quality evaluation, 2) price/value evaluation, 3) overall evaluation, 4) overall satisfaction, and 5) repeat visit/repurchase intention. This results in 30 tourist behavior domains in the "After-Travel" stage (6 variables $\mathrm{X} 5$ behavioral measures for each). These 30 travel behavior domains are identified in the after-travel stage are labeled AT1 to AT30 on Table 1.

\section{TOURIST BEHAVIOR STUDIES: LITERATURE REVIEW}

Hofstede's $(1980,2001)$ five cultural dimensions have been applied to the study of tourist behaviors. This section 
of the paper summarizes the findings of the research studies identifying the specific cultural dimensions used for explaining specific tourist behaviors. The literature review provided in this section is by and large organized as per the list of tourist behaviors identified in previous section and summarized in Table 1.

\section{Studies of Tourist Behaviors Before-Travel}

\section{Travel motivations/benefits sought:}

The subject of travel motivations has been extensively studied in travel and tourism research. As a psychological factor explaining human behavior (Kotler \& Keller, 2009; Manrai \& Manrai, 1996, 2011), travel motivations provide very significant insights into travel decision making processes and various behaviors during the travel experience. Hofstede's cultural dimensions are extremely relevant for the study of travel motivations because cultural values influence all aspects of human life including personal factors like lifestyle and psychological factors like motivation (Manrai \& Manrai, 1996, 2011). For example, a study by Kim and Lee (2000) found that individualistic tourists were more likely to seek novelty whereas the motivation of the collectivistic tourists is primarily to be with the family.

A study by Prebensen (2005) identified four distinct clusters within a charter tour group of Norwegian tourists headed for warmer climates. These four clusters were labeled "Active Sun and Family", "Cultural Patron", "Experiencing" and "Sun and Comfort" by the author. The finding of the study indicated that the four segments differed in terms of their travel motivations, the type of activities they engaged in and their planning for the trip. The four segments also showed differences in terms of their trip characteristics such as travel group/companions and trip duration. Further, the tourists' satisfaction from the destination and activities/organization, as well as the revisit intentions, significantly differed across the four segments. The author explains these results by suggesting that the cultural values of Individualism prevails in tourists choice of products and activities despite the different segments being pooled together in a group or collectivistic setting. The active fun and family segment indicated higher satisfaction ratings possibly because the tourist motivations and type of activities have a relationship with tourist satisfaction.

Another study by Prebensen, Larsen, and Abelsen (2003) provides some interesting and useful insights on the concept of individuality in the tourism context. This study included 455 German tourists in Norway who were asked questions related to the tourists' perception of themselves as typical or non-typical German tourists, what constituted a typical German tourist in Norway, as well as the importance of various travel motives and activities they participated in/plan to participate in. The list of travel motivations included two motivations related to the knowledge function (beautiful scenery and the Norwegian culture); one motivation related to the social adjustment function (visit family and friends); two motivations related to the value expression function (no mass tourism and the Norwegian mentality); and four motivations related to the utilitarian function (former experience, recommendations from friends and/or family, good prices, and good offers from travel agency). The findings of the authors indicated that while nearly $90 \%$ of the respondents viewed themselves as non-typical German tourists, there were no differences between the typical and non-typical tourists on what constituted a typical German tourist to Norway, travel motivations and activities they participated in or intended to participate in. The authors conclude from these findings that tourists from individualistic countries (like Germany) may have a need to be perceived as individualists; hence, individuality in tourism context may be a matter of self-perception.

The notion of individualism applied to a tourist's self-image was also explored in a study by Litvin and Kar (2003). These authors studied the moderating influence of Individualism-Collectivism value dimension in predicting the effect of Self-Image and Destination-Image congruity on tourist satisfaction from the destination. Their database was comprised of 189 exit surveys at Singapore airport and included non-business travelers. These authors replicated Chon's (1992) study supporting Self-Image and Destination-Image congruity as a determinant of tourist satisfaction. The findings 
of this study supported the hypothesis that tourist satisfaction will be higher when there was congruity between tourist's Self-Image and Destination-Image (both images were individualistic or both images were collectivistic). Additionally, within the two congruent scenarios, tourist satisfaction was higher when the two images were individualistic than when the two images were collectivistic. This later result is explained in terms of greater hedonistic tendencies on part of the individualistic tourists.

\section{Travel occasion/event/travel life cycle:}

The concept of Travel Life Cycle (TLC) was coined by March (2000) and basically implies that, depending upon the life cycle stage, an individual will take certain types of institutionalized or group tours. TLC is particularly useful for segmenting the traditional, group-oriented collectivistic societies such as Japan, China, Korea, etc. March compiled data from various sources and identified eight distinct segments of Japanese tourists. These eight segments, in order of their market share (in 1997), are: Family Trip (25\%), Silvers ${ }^{1}(16 \%)$, Incompany Trip (12\%), Honeymooners (2.6\%), Language Study (1.5\%), School Excursions (0.8\%), Overseas Wedding (0.5\%), and Graduation Trip (0.4\%). Based on industry interviews, the author estimated that the proportion of customers buying group tours was as follows: $90-100 \%$ for school excursions and overseas weddings, $80-90 \%$ for In-Company trips, $75-85 \%$ for language study, $75-80 \%$ for family trip and honeymooners, $60-70 \%$ for silvers and $50-70 \%$ for graduation trips. March describes the collectivity of Japanese society in no uncertain terms, when states that from early age the Japanese individual is obliged to adopt culturally prescribed behavioral patterns for particular social situations, either at school, in the workplace, or within relationships. The paper discusses the implications of the collectivity-driven travel life cycle concept in terms of travel companions, travel duration, activities and experiences sought, and various purchase related behaviors for each of the eight segments.

1 The Silvers segment refers to tourists aged 60 years and over.
The family trip, or kazokuryoku, includes both parents and at least one child under 12 years old. The most preferred destination for this group is Hawaii. However, parents with very young children or babies prefer nearer destinations such as Guam or Saipan. An emerging trend noted by March is the three generation group where grandparents join the parents and the kids for overseas travel. The two main motivations for family trips mentioned by tourists in this group were the opportunity for kids to experience foreign cultures and the reasonable costs of overseas trips.

As mentioned before, the "silvers" segment refers to $60+$ years of age tourists. According to JTB (1998), $40 \%$ of the silvers travel with their spouses, $24 \%$ travel with family members and $20 \%$ travel with friends and acquaintances. Almost two-thirds of silvers buy full packages and USA is the most preferred destination. This segment stays for longer duration abroad and is both able and willing to spend more money on overseas travel. They can afford it because of higher disposable income and they want to prevent their kids from paying higher inheritance taxes.

The "in-company" (shokubaryoku) trip is a Japanese custom in which company workers take a vacation once a year with their colleagues. This trip usually lasts any where from a few days to a week; it is mostly sponsored by the company, while employees pay a small proportion of the cost. The topmost destination for this segment was the USA.

The "overseas wedding" segment is the fastest growing market. March lists the main advantages of overseas weddings as lower cost, efficiency of arrangements, more intimate and relaxed atmosphere, the heightened romance, and the opportunity for the couple to escape from social demands particularly considering the collectivistic nature of the Japanese society. Overseas weddings typically include immediate family members/ relatives and close friends. The top destination for overseas weddings was Hawaii and on an average 7-8 people accompanied the couple to the overseas wedding. March indicates that the "honeymoon travelers" spend more on accommodation, meals, tours, and shopping 
than any of the other segments. Honeymooners therefore are the most lucrative and sought after segment in the Japanese group tour business. The typical length of stay for this segment is about one week, and the most preferred destination is Hawaii.

The "school excursions" (shugakuryoku) refers to the organized travel activity undertaken by high school juniors and seniors. Schools typically choose a particular overseas destination for at least two or three consecutive years because of the time and money involved in making new arrangements every year. The top three destinations for school excursions are Korea, China, and Australia, in that order. The "graduation trip" (sotsugyoryoku) refers to overseas travel undertaken by university graduates before they begin full time employment. Typically graduates travel with a few close friends. The average length of these graduation trips are 8 days and the top three destinations are USA, Hawaii, and Asia. This group of tourists travels on a budget and employ money saving options such as rail passes. They are also the tourists group with the lowest proportion of package tour purchases. Lastly for the "language study" segment, the three top destinations included the three English speaking countries: USA, U.K., and Australia, in that order.

\section{Travel risk perception, safety concerns, and travel anxiety:}

Several researcher studies have addressed the issue of perceived travel risk (Moutinho 1987; Roehl \& Fesenmaier, 1992; Ressinger \& Mavondo, 2005). Researchers have identified the determinants of risk perception in tourism as well as the individual characteristics related to personal and psychological factors, such as personality, lifestyles, and motivations (Bello \& Etzel, 1985; Carr, 2001), as well as nationality (Seddighi, Nuttall, $\&$ Theochaous, 2001) and cultural differences.

The perception of travel risk affects a tourist's assessment of travel safety and also leads to travel anxiety. The governments of several countries have issued alerts for their citizens related to the safety concerns in certain international travel destinations. While such safety alerts are certainly warranted, they further enhance the safety concerns and travel anxiety of international tourists. In turn safety concerns and travel anxiety adversely influence international tourism activities.

A study by Ressinger and Mavondo (2005) examined the relationship between cultural orientation, travel motivation, travel safety, travel anxiety and intention to travel internationally. The sample for their research study comprised of 246 Australian and 336 foreign respondents who were randomly selected from individuals visiting several tourist attractions in Melbourne, Australia and administered a questionnaire. The cultural orientation was measured using items representing the four cultural dimensions identified by Hofstede (1980), the fifth cultural dimension of long-term versus short-term orientation identified in Bond and the Chinese Cultural Connection (1987), and the concept of low versus high context cultures developed by Hall (1976). The travel motivation was measured using items adapted from Kale, McIntyre and Weir (1987). The perceptions of travel risk were measured along 13 dimensions identified in the prior tourism literature: crime, cultural, equipment, financial, health, performance, physical, political, psychological, satisfaction, social, terrorism, and time. The safety perceptions were measured for certain selected regions and situations. Travel anxiety was measure using 12 item bipolar scales capturing feelings of tourists. The intentions to travel internationally was measured using a 100 point scale with $0=$ no intention and 100 $=$ definite intention. Several relationships between the above variables were hypothesized.

The results of path analysis indicated that for both Australian and foreign samples, significant relationships existed between culture and safety, tourism risk and anxiety, socio-cultural risk and anxiety, and anxiety and intention to travel internationally. For the foreign sample only, significant relationships existed between travel motivation and health/financial risk, motivation and anxiety, motivation and safety, and safety and intentions to travel internationally. For the Australian sample only, the relationship between culture and socio-cultural risk was significant. 


\section{Trip planning/prior arrangements:}

Considering the complexity of the tourism products and various risks associated with international travel, it is natural for many tourists to take measures to reduce such risks. The extent to which a tourist is concerned with such risk reduction behaviors is a function again of his/her personal and psychological characteristics as well as cultural orientations. In this context, Hofstede's (1980) cultural dimension of uncertainty avoidance is extremely relevant. Tourists from cultures which are low on uncertainty avoidance are likely to have a higher threshold for risk and uncertainty and thus will engage in risk reducing behaviors to a lesser extent. Conversely tourists from cultures, which are high on uncertainty avoidance are likely to have a low threshold for risk and uncertainty and thus will engage in risk reducing behaviors to a greater extent.

Tourists undertake such risk reducing behaviors both in before-travel and during-travel stages. The before-travel risk reducing behaviors include extensive trip planning, use of travel agents and tour operators, making prior travel arrangements, pre-payment for tourism components etc. Two research studies dealing with these issues are Money and Crotts (2003), and Crotts and Litvin (2003). Both of these studies used a subset of database compiled by the U. S. Department of Commerce's Office of Travel and Tourism Industries (OTTI). Money and Crotts used data set for the years 1996-1998 and their study included native German and Japanese discretionary travelers. Crotts and Litvin used data set for the year 2000, and their study included outbound tourists from U. S. whose place of birth differed from their nation of citizenship. The participants were born in 74 countries, resided in 81 countries, and were citizens of 68 nations. The findings of both studies indicated that tourists from high uncertainty avoidance cultures had taken risk and uncertainty reducing measures such as inclusion of pre-paid tours and pre-booked lodgings to a greater extent than tourists from low uncertainty avoidance cultures.

\section{Studies of Tourist Behaviors During-Travel}

This sub-section includes five tourist behavior domains, four of which capture the risk-reducing behaviors related to the during-travel stage. These four domains are trip duration/length of stay, number of destinations in the itinerary, travel party size/travel companions, and travel frequency. The fifth tourist behavior domain included in this subsection is behavior of tourists on group tours.

\section{Trip duration, number of destinations in the itiner- ary, travel party size, travel frequency:}

The two research studies related to the risk-reducing behaviors in the before-travel stage discussed earlier (Money \& Crotts, 2003; Crotts \& Litvin, 2003), also examined several risk-reducing behaviors related to the during-travel stage. The findings of these two studies indicated that tourists from the high uncertainty avoidance cultures had taken risk and uncertainty reducing measures related to the during-travel stage also to a greater extent compared to the tourists from the low uncertainty avoidance cultures. Specifically, the findings of these two studies indicated that tourists from high uncertainty avoidance cultures compared to tourists from low uncertainty avoidance cultures had shorter stays in USA, visited fewer destinations in the itinerary, and traveled with a larger party size.

An alternate construct used to explain the cultural differences in business settings is "Cultural Distance" or the gap between the business cultures of the visitor and the host. Early research by Kogut and Singh (1988), using Hofstede's four cultural dimensions, yielded inconsistent findings. Subsequently, Hofstede (1989) suggested that the use of uncertainty avoidance dimension to operationalize cultural distance will be more appropriate because this particular dimension is more disruptive than the others in the context of international business.

Crotts (2004) opertionalized "Cultural Distance" using national uncertainty avoidance scores and studied the overseas travel behavior of 302 outbound travelers from USA to 26 different countries. Only the U. S. born 
residents traveling abroad for the first time, and primarily traveling for discretionary purposes (non-business), were included in the survey. This control of the sample was done to eliminate confounding in the base score of participants on Uncertainty Avoidance dimension, which was used for determining the Cultural Distance. All the participants were assigned a base Uncertainty Avoidance score of 43 as per Hofstede's (1980) study. The cultural distance was compared by subtracting this base score of 43 from Uncertainty Avoidance score of the host countries to which the participants were headed. Crotts (2004) predicted that the cultural distance will be positively correlated with risk-reducing behaviors such as larger travel groups, less frequent travel, shorter trips, and lower number of destinations in the itinerary. Finding of his study supported these predictions. When the cultural distance was low, Uncertainty Avoidance Index of the host country was closer to that of the U. S. A., the international tourists traveled alone, traveled more often, took longer trips and visited a greater number of destinations.

\section{Behavior of tourists on group tours:}

The four research studies reported in this subsection (Pizam \& Sussmann, 1995; Wong \& Lau, 2001; Kim $\&$ McKercher, 2011; Meng, 2010) discuss the behavior of tourists on group tours. The first three studies differ from each other in three ways, namely, the methodology, the composition of the sample, and the basis of cultural comparison. First, in terms of the methodology, Pizam and Sussmann (1995) used an indirect method of assessment, which was based on perceptions of tour guides. Wong and Lau (2001) study directly assessed the tourist behavior: the tourists completed a survey questionnaire. As for Kim and McKercher (2011), they compared and contrasted the responses of the tourists and service providers relating to expectations of desirable tourist behaviors and the perceptions of actual tourist behaviors.

In terms of the composition of the sample, the tour group in Pizam and Sussmann (1995) study comprised of four different nationalities: citizens from the U. S. A., France, Italy and Japan. The tour groups in the studies of
Wong and Lau (2001) and Kim and McKercher (2011) comprised of only Hong Kong Chinese tourists and only Korean tourists respectively. The third difference in the three studies related to the basis of cultural comparison. In Pizam and Sussmann (1995), the behavior of the four nationalities based subgroups of tourists were compared with each other. In Wong and Lau (2001), the behavior of the Hong Kong Chinese tourists was examined in relation to the Chinese Cultural Values; in the Kim and McKercher (2011) study, the focus was in understanding the differences in the expectations of the desirable tourist behaviors vis-à-vis perceptions of the actual tourist behaviors. The fourth study reported in this sub-section on behavior of tourists on group tours is a conceptual article, which develops four research propositions for further empirical testing.

The respondents in Pizam and Sussmann (1995) study were 123 tour guides in London, U. K., who regularly guided tours within the city. A total of 252 questionnaires were completed by the tour guides assessing the behavior of U.S., French, Italian, and Japanese tourists during their tour. Thus, on an average, the tour guides completed two different questionnaires for tourists of two different nationalities. These 252 questionnaires included 97 U.S. tourists, 57 French tourists, 43 Italian tourists, and 55 Japanese tourists. The questionnaires included twenty typical tourists' behaviors and the respondent tour guides indicated their assessment of the tourist behaviors by circling a number from 1 to 5 on each of these 20 arched semantic differential scales.

The data were analyzed using factor analysis and yielded five factors. These five factors were labeled as follows: "Social Interaction Factor" (SIF), "Activity Preference Factor" (APF), "Commercial Transaction Factor" (CTF), "Bargaining Factor" (BPF) and "Knowledge of Destination Factor" (KDF). The BPF also included planning behavior. The ANOVA analysis was performed for all 20 items included in these four factors.

The SIF included six items dealing with interaction, socialization, and congregation, focus on people 
versus artifacts, food preference, and trip length. The CTF included seven items dealing with souvenir buying, gift buying, trusting tourist trade people, shopping, photography, group travel, and letter writing. The APF included three items regarding adventurous versus safe, active versus passive, and novelty versus familiarity. The BPF included two items, the first one dealing with bargaining and the other with planning. The KDF included two items: dealing with authenticity and knowledge about destination. With the exception of two out of 20 behavioral variables (novelty versus familiarity on APF and the knowledge about destination on the KDF), the differences in the behavior of tourists from four nationalities on the remaining 18 variables were significant at $\mathrm{p}<0.001$ level.

The pair-wise (national pairs) comparisons for each of the twenty travel behaviors were carried out by the authors. This resulted in an overall of 120 comparisons (20 variables X 6 nationality pairs) consisting of 36 for social interaction factor, 42 for commercial transaction factor, 18 for activities preference factor, 12 for bargaining factor, and 12 for knowledge of destination factor. The social interaction factor showed the largest percentage of differences ( 29 out of 36 , or $80.5 \%$ ). This was followed by the bargaining factor ( 9 out of 12 , or $75 \%$ ), the commercial transaction factor (31 out of 42 , or $73.8 \%$ ), the activities preference factor ( 8 out of 18 , or $44.4 \%$ ), and the knowledge of destination factor (3 out of 12 , or $25 \%$ ).

Since each of the four nationalities was compared with the other three nationalities on each of variables, a total of 60 comparisons existed for each nationality (20 variables X 3 comparison for each variable). The authors also computed the overall percentage of differences for the nationalities. Japanese tourists were assessed as being most different from the other nationalities ( 42 out of 60 comparisons, or $70 \%$ ). The U. S. citizens were second most different from the other nationalities (41 out of 60 comparisons, or $68.3 \%$ ), followed by the French ( 40 out of 60 comparisons, or $66.7 \%$ ). The Italian tourists were the least different from the other three nationalities ( 37 out of 60 comparisons, or $61.7 \%$ ).
The mean scores capturing the perceptions of the tour guides assessing the travel behavior of the tourists from four nationalities on the 20 scales were examined to identify extreme (highest and lowest) ratings. The U. S. tourists scored the highest on each of the six social interaction variables: interaction, socialization, congregation with other nationalities, interest in people, preference for local cuisine and taking long trips. The Japanese tourists were lowest on four out of six variables relative to other nationalities: they kept to themselves, avoided socializing, congregated with same nationality and were interested in artifacts. As regards to food preference, the other three nationality groups, besides U. S. tourists, were perceived to avoid local foods and beverages. The Italian tourists scored the lowest on the trip duration variable, they took the shortest trips.

The perceptions related to the second factor, that is the CTF, showed that French tourists had the lowest scores for all seven variables, included in this factor, relative to other nationalities. They did not buy souvenirs, did not buy gifts, did not trust tourist trade people, did not shop, did not take photos, traveled alone, and did not write letters. The Italian tourists scored fairly close to French tourists in terms of their lack of trust of tourist trade people and the Japanese tourists scored fairly close to the French tourists in terms of not writing letters. The U. S. and Japanese tourists scored fairly close ratings on the high end of the scale for six out of seven variables included in this factor. Five out of these six variables were the same for U. S. and Japanese tourists: both tourist groups bought souvenirs, bought gifts, trusted tourist trade people, shopped constantly and took photos. In addition, the Japanese tourists also scored highest in terms of traveling in groups and U. S. tourists scored highest in terms of writing letters.

As regards the APF, Japanese tourists were the least adventurous and French and Italian tourists scored fairly close highest ratings amongst the four tourist groups. The Japanese tourists preferred passive activities compared to the other three tourist groups who preferred more action. There were no differences in the four tourist groups in terms of novelty versus familiarity seeking. 
As regards the fourth factor (BPF), the Japanese and American tourists paid the asking price whereas the Italian tourists bargained the most compared to other tourist groups. Japanese tourists planned their trips the most rigidly; conversely, Italian tourists took loose and unplanned trips the most compared to other tourist groups. Finally, in Knowledge of Destination Factor, French, Italian and U. S. tourists wanted to see the "authentic" things, whereas the Japanese tourists were satisfied with "staged" events. There were no differences in the four tourist groups on this factor.

Many of the results of this research study are explained by the authors in terms of Hofstede's (1980) cultural dimensions of Individualism versus Collectivism and Uncertainty Avoidance. U. S., French and Italian cultures are considered as individualistic, whereas the Japanese society is considered collectivistic. U. S. tourists are considered to be low on uncertainty avoidance, whereas French, Italian, and Japanese tourists are considered to be high on uncertainty avoidance The individualism and low uncertainty avoidance tendencies of the U. S. tourists explain their travel related behaviors such as preference/choice of local foods and beverages, taking long trips, preference/choice of action oriented tourism, wanting to see authentic things at destination, etc. On the other hand, the collectivistic and high uncertainty avoidance tendencies of Japanese tourists explain their travel related behaviors such as preference/choice of own cuisine, traveling in groups, preference/choice of safe activities, rigid planning of the trips, satisfaction in seeing "staged" events, etc.

Wong and Lau (2001) reported the behavior of 200 Hong Kong Chinese tourists on group tour packages in relation to Chinese cultural values (Bond and the Chinese Cultural Connection, 1987). The data were collected by interviewing respondents in Cantonese language in the busiest streets of Hong Kong. A bilingual questionnaire was also kept at hand for the reference of respondents. Only the respondents who had prior experience of taking group tour packages were included in the survey. The measures of tourist's behavior on group tour packages included 22 items, 20 of which were the same as those used in the study of Pizam and Sussmann (1995). The two additional items related to whether or not the tourists complained for any unsatisfactory issue during the trip and whether or not tourists joined self-paid activities as suggested by the tour. The item related to the complaining behavior was considered relevant to study because Chinese people rarely complain in front of others as they want to avoid loosing "face" or causing others to loose face (Bond \& Lee, 1978). Arched semantic differential scales were used for measurement of tourists' behavior on these 22 items.

In this research study ratings, the participants scored high on the novelty seeking (4.43), desire to see authentic things (4.31), preference/choice of local foods and beverages (3.92), taking many photos (3.98), visiting places rigidly according to tourist brochures (3.98), traveling in groups (3.80). On the other hand, the participants scored low on adventure (2.39), writing letters (1.96) and knowledge of destination (2.60). Only 7 of the 200 respondents had taken the group tours alone. These results provide insights into the travel motivation and activities preference/choice of Hong Kong tourists. The authors explained some of these results in terms of the collectivistic, risk-averse nature of the Hong Kong Chinese culture. Group tours and traveling with other companions is considered a way of reducing the risk, especially when the knowledge of destination is low. Adhering strictly to the itinerary also provides the tourists with a sense of safety and reduced risk.

Wong and Lau (2001) also measured the importance of 13 Chinese Cultural values to the respondents. These 13 values were a subset of the 40 item list developed in the Bond and Chinese Cultural Connection (1987) study, and they were selected based on a pretest that identified the values relevant to the tourism context. The respondents indicated the extent to which these 13 Chinese Cultural Values were important to them by circling a number on 5-point Likert scale with 1 being very unimportant and 5 being very important. These 13 Chinese cultural Values included adaptability, being conservative, contentedness, courtesy, harmony with others, patience, protecting face, prudence, reciprocity, respect for tradition, thrift, tolerance of others and trustworthiness. 
A factor analysis of the data on these 13 Chinese Cultural values yielded four factors. The first factor was labeled "Social Integration" and included five variables: adaptability, contentedness, courtesy, prudence, and trustworthiness (adaptability variable was later deleted due to its factor loading of less than 0.50 ). The second factor was labeled by the authors "Confucian Work Dynamism" (referred to as "Work Dynamism" in the present research paper) and included three items: patience, respect for tradition and thrift (the thrift variable was later deleted because the internal reliability test indicated that deleting this variable will increase the alpha coefficient from 0.58 to 0.62 ). The third factor was labeled "Personal Well-Being" and included three items: being conservative, protecting face, and reciprocity. The fourth factor was labeled "Moral Discipline" and included two variables: harmony with others and tolerance of other.

In order to jointly examine the relationship of Hong Kong Chinese tourists' behavior on group tour packages with Chinese Cultural Values, canonical correlation analysis was performed. The results yielded four functions of which two were significant at $p<0.05$. Using a cutoff of redundancy index $>1.3 \%$ for both travel related behavior and Chinese Cultural Values, only one of the two functions was used for further analysis. The canonical loadings and canonical cross-loadings of this function for each of the 22 travel related variables and each of the four Chinese Cultural Value factors were computed. The variables with canonical loadings $>0.40$ within the same set (travel related behaviors set or Chinese Cultural Values factors set) and canonical cross-loadings $>0.30$ between two sets (travel behaviors set and Chinese Cultural Values factors set) were identified.

The results of canonical loadings for 22 travel related behaviors indicated that three correlated variables within the set of travel behaviors were travel in groups versus travel by themselves, adventurous versus safe and joining all self-paid activities suggested by tour versus not joining. Hong Kong Chinese tourists taking group tours preferred safe activities and they also preferred to take all self-paid activities as suggested by tour. The canonical loadings for the four cultural value factors indicated that two out of the four factors met the criterion, Social Integration factor and Personal WellBeing factor, implying that these two factors had greater relevance for the cultural values concept compared to other two factors, Work Dynamism factor and Moral Discipline factor.

As regards the results of canonical cross-loadings, only two travel behaviors, travel in groups/travel by themselves and adventurous versus safe, correlated with Social Integration and Personal Well-Being. Taking into consideration the relative importance of the ratings of different cultural values, the authors conclude that Social Integration values, such as courtesy, prudence, and trustworthiness, exert an important influence on the behavior of tourists on group package tours, whereas Personal Well-Being values such as being conservative and protecting face are not as important.

The authors further discuss why the four Chinese Cultural Value factors were found relevant or irrelevant in their study. The social integration factor explained the largest proportion $(25.1 \%)$ of the variance and the values included in this factor (courtesy, prudence, trustworthiness, and contentedness) were considered relevant for social interaction in a collectivistic setting like taking a group package tour. The second factor, Work Dynamism, included values such as respect for tradition and patience, and it explained $13.4 \%$ of the variance. The authors suggest that while Work Dynamism values are more unconscious and sophisticated, they are less important than social integration values and the tourist may not notice these Work Dynamism values during the tour. Therefore, this factor was not found relevant for behavior of tourists on group tour packages.

As regards to the third Chinese Cultural Values factor, labeled Personal Well-Being, it explained 9.8\% of the variance and included values such as being conservative, reciprocity and protecting face. These values were not considered important on the tour because the relationships of individuals within the group tour are temporary. Lastly, the fourth factor, Moral Discipline, 
explained $9.3 \%$ of the variance and the two values included were tolerance of others and harmony with others. Again, these values may not have been found relevant for the temporary nature of the relationships that exist in a group package tour.

The third study reported here is by Kim and McKercher (2011). These authors studied the behavior of 345 Korean tourists taking group tour packages in Australia. The tourist behavior was studied in terms of Korean tourists' expectations of their desirable behavior as well as Korean tourists' perceptions of their own actual behaviors. These expectations of desirable tourist behaviors and actual tourist behaviors were also measured from the standpoint of the 73 service providers, including hotel employees working in the front line positions such as front desk staff, customer relations, food delivery, etc., who had experience with Korean customers.

The research instrument consisted of a questionnaire with two parts. In Part I, expectations on 23 different aspects of desirable tourist behaviors were obtained from tourists themselves as well as from service providers. In Part II, perceptions of actual tourist behavior were obtained from tourists themselves as well as from service providers on the same set of 23 variables. This study included four categories of variables: 1) desirable tourist behaviors rated by tourists themselves; 2) desirable tourist behaviors rated by the service providers; 3) actual tourist behaviors rated by tourists themselves, and 4) actual tourist behaviors rated by the service providers. The comparisons and contrasts included: $\mathrm{C} 1$ : 1 versus 2; $\mathrm{C} 2$ : 3 versus 4 ; $\mathrm{C} 3$ : 1 versus 3 ; and $\mathrm{C} 4: 2$ versus 4 . The 23 items included in the research survey were developed based on review of previous literature as well as in-depth interviews with five Korean tour guides specializing in Australian market and 10 Korean tourists with prior experience of package tourism in Australia. The research instrument was pilot tested and modifications were made.

The items included in the survey covered three categories of behaviors: the collective actions, the cultural dietary habits, and the insufficient foreign language skills or lack of understanding of tourist ethics. The 23 behaviors covered in the survey included: move around the hotel noisily, move around the hotel in crowds, yield to others when using the elevator, have meals with other Korean customers in groups at the hotel restaurant, be noisy in the hotel restaurant, leave food in one's plate in a hotel restaurant, eat slowly in a hotel restaurant, eat meals at set times every day, move seats around in a hotel restaurant, leave litter or cigarette butts around the hotel, make noise in one's room, tip handsomely, complain to hotel employees on receiving unsatisfactory service, express thanks to hotel employees upon receiving help, ask questions to Australian hotel employees when unaware of hotel facilities or services, use hotel facilities without making a mess, know how to use hotel facilities, drink alcohol in one's room, eat ones national food in one's room or in hotel restaurant, be unwilling to pay a bill after using the mini bar in the room, use one's room in an untidy fashion, take magazines upon departure from the room, and not return the plastic room key. The Korean tourists and Australian hotel employees gave their responses for desirable and actual tourist behaviors for each of the 23 items on a 7-point scale where 1 represented disagreement and 7 represented agreement.

The results of this study indicated that 11 out of 23 comparisons were significant for $\mathrm{C} 1$ (expectations of desirable tourist behavior - Australian service provider versus Korean tourists). On C2 (perceptions of actual tourist behaviors - Australian service providers versus Korean tourists), 14 out of 23 comparisons were significant. As regards to $\mathrm{C} 3$ (desirable versus actual tourist behavior - Korean tourists), 22 out of 23 comparisons were significant. Finally, for C4 (desirable versus actual tourist behavior - Australian service providers), all 23 comparisons were significant. The authors also note that, besides statistical significance, divergence of opinions in these comparisons provides even more robust insights. Starting with 1 out of 11 statistically significant and divergent finding for $\mathrm{C} 1,14$ out of 23 findings showed divergence of opinions at the statistically significant levels for $\mathrm{C} 4$. The number of statistically significant and divergent findings was 5 out of 14 for $\mathrm{C} 2$, and 9 out of 22 for $\mathrm{C} 3$. 
These results provide some very interesting insights on tourist behavior in terms of the expectations of desirable behavior and perceptions of actual behavior by tourists themselves and by service providers. First, the comparison of the opinions/ratings of the two groups (tourists themselves and service providers) on expectations of the desirable tourist behavior $(\mathrm{C} 1)$ showed only 1 out of 23 divergent results. This implies that there was a fair amount of agreement between the two groups as to what is considered as the desirable tourist behavior. Korean tourists constitute a sizeable percentage of inbound tourists in Australia and this finding conveys that Australian service providers have relatively good idea of the expected code of conduct based on the cultural norms of the tourists' culture of origin (Korean culture). Second, the comparison of actual versus desirable tourist behaviors, namely C3 and $\mathrm{C} 4$, showed that both groups gave opinions/ratings that indicated a deviant actual behavior compared to the desirable behavior based on cultural norms of tourists. For C3, comparing the differences within group (actual versus desirable tourist behavior rated by tourists themselves), 22 out of 23 comparisons were statistically significant. For $\mathrm{C} 4$, comparing the differences within the group (actual versus desirable tourist behaviors rated by service providers), all 23 comparisons were statistically significant. This finding suggests that Korean tourists on group tours behave quite differently compared to their cultural norms and this view is shared by both tourists and the service providers.

Package tourism is extensively used in China, Japan, and Korea. These are collectivistic societies which encourage, and often require, adherence to social norms and accepted patterns of collectivistic behaviors, geared towards the larger interests of the society rather than the individuals. These group-oriented societies are also extremely hierarchical and respect authority. Tourism planning and execution of all the arrangements require careful attention to details as well as personal, social, financial, and safety risks. Package tourism offers a structured mode of travel, minimizes the risk and uncertainty, and provides a platform for collective social interaction.
However, typically collectivistic, high power distance societies are also extremely competitive and the individuals feel a need to escape from their stressful routine life (Han \& Heather, 2001). Therefore, many individuals seek novelty through pleasure travel to international destinations. While these tourists may join a package because of advantage of collectivity, structure and risk reduction, their motivation for pleasure travel to an international destination is often driven by adventure and novelty seeking. Consequently, the behavior of these tourists on package tours would deviate from the norms of their home culture.

The authors bring in the concept of "Tourist Culture" (Jafari, 1987) in addition to the "National Culture" to explain their findings in this study. The "National Culture" is captured through five dimensions of Hofstede (1980, 2001). The authors postulate that the tourist behavior in group tours is a function of national culture of the tourists and the temporary tourist culture, which the individuals may adopt when on a holiday. According to Jafari (1987), tourist culture “...defines and redefines roles, rules, notions, motions, forms, forces, expectations, processes, and the nature of animation" (153). The authors further quote Jafari (1987) on the transformation of the tourist "... as the emergence into touristhood deepens, the tourist ... is transformed into a new person with a new identity (the tourist) that he is playing on a new stage (the magnet) and thus he is living up to the magnet of a new culture (the "tourist culture")" (157). The quest for unusual, out of the ordinary experiences, which would not be normally permitted back home, leads many tourists to embrace "tourist culture" behaviors. Jafari and Way (1994) suggest that for international tourists, an escape from the norms of their home culture may in fact provide them with relief from their ordinary and routine life, and provide tourists with relaxation and novelty.

The findings of Kim and McKercher (2011) suggest that Korean tourists tend to deviate from their home cultural norms while taking package tours in Australia. They tend to be noisier, rearrange restaurant layouts, eat and drink in their rooms and engage in more extreme collectivistic behaviors. At the same time, they are less 
likely to eat meals at set times, less likely to yield to others in the elevators and less likely to observe care in use of the hotel facilities. The authors conclude from these and other findings that the tourist behavior on group tours represents a combination of national culture and tourist culture.

The fourth study reported in this sub-section is by Meng (2010) and develops four propositions on the relationship between Individualism versus Collectivism with group travel behavior. The author reviews findings relating to different aspects of group travel behavior and four of the five cultural dimensions of Hofstede: Confucian Dynamism, Individualism versus Collectivism, Power Distance, and Uncertainty Avoidance. Examples are drawn mainly from collectivistic societies of Asia such as China, Japan and Korea. The author proposes a conceptual model in which the individualism versus collectivism in a culture affects group travel behavior in conjunction with two other categories of variables (social, political and economic factors) and personal background (age, education, income, language skills and past overseas travel experience). These other categories of variables are also conceptualized to moderate the relationship between individualism versus collectivism and group travel behavior.

\section{Studies of Tourist Behaviors After-Travel}

In this subsection, five types of post-travel behaviors are included: quality evaluation, price/value evaluation, overall evaluation/image, satisfaction/dissatisfaction and repeat purchase/revisit intention. Each of these five post-travel behaviors can be applied to the domains of travel mode, destination, transportation, accommodation, food, and activities/tours.

\section{Destination: quality, perceived value, overall evaluation, satisfaction, revisits intention:}

A large number of studies have compared Asian versus Western tourists examining behaviors such as service quality evaluations, perceive value evaluations, performance/overall evaluations, satisfaction/dissatisfaction and repeat travel/visit intentions. Asian tourists in gen- eral tend to have higher expectations and evaluate the service performance less favorably compared to their Western counterparts. These differences are attributed to two cultural values. First, Asian cultures are people oriented Collectivistic societies and Asian tourists are likely to expect greater courtesy and consideration compared to societies, which are less people oriented and individualistic. Second, Asian cultures are higher in Power Distance and Asian tourists are likely to view themselves much more powerful than their service providers compared to Western cultures where such contrasts may not exist or may be less extreme. Thus, overall, tourists from Asian countries are stricter in their performance evaluations.

Hsu and Kang (2003) investigated differences in perception of service quality, perceived value, overall image/destination attractiveness, satisfaction, and revisit intention between Asian and Western tourists to Hong Kong. Their database consisted of 183 non-transit international visitors coming from seven major source markets: Australia, China, Malaysia, Singapore, Taiwan, USA, and Western Europe. These visitors had traveled to Hong Kong as family independent travelers (FITs) for vacation/pleasure/family purposes. The findings of this research study indicated that Western tourists evaluated service quality, perceived values, good value for money, satisfaction with the visit and attractiveness of Hong Kong as a tourist destination more favorably compared to Asian tourists. However, Western tourists indicated a lower likelihood of returning to Hong Kong for a repeat visit compared to Asian tourists. The authors contemplate that the proximity of Hong Kong to Asian countries may possibly be the reason explaining the higher likelihood of revisit expressed by Asian tourists.

\section{Transportation: quality evaluation, price evaluation, repeat purchase intention:}

Crotts and Erdmann (2000) examine the relationship between the Masculinity versus Femininity dimension and traveler's evaluation of airline ticket prices, evaluation of flight and loyalty to airline. They used a subset of the database compiled by the U.S. Department of 
Commerce's Office of Travel and Tourism Industries (OTTI) for 1996-98. The countries of origin of the U.S. bound tourists were Brazil, Germany, Japan, Taiwan and the United Kingdom. The findings of these authors indicate that the respondents from masculine cultures negatively evaluated the airline ticket prices and overall service quality. They also responded unfavorably to the question related to the loyalty to the airline for repeat travel. These findings were replicated in a subsequent study by Crotts and Litvin (2003), which used a subset of the OTTI data for the year 2000. These two research studies explain the findings in terms of the traits of achievement and aggression associated with masculine cultures. It is, therefore, interpreted that such traits may result in higher levels of expectations and/or stricter standards of evaluations.

\section{Accommodation: service quality evaluation:}

A study by Mattila (1999) examined the difference between Asian and Western tourists in their perceptions of the service encounter and service quality evaluation for two luxury hotels in Singapore. The researchers observed the encounters between hotels' front desk employees and guests after which they asked the guests to complete a questionnaire. The findings in this study indicated that Asian tourists rated both the service encounter and service quality significantly lower than Western tourists. As discussed earlier, these results can be attributed to the higher levels of expectations of Asian tourists due to the people oriented collectivistic nature of the Asian societies, as well as the inherent social inequalities, which exist in these high power distance cultures leading to higher levels of expectations. Mattila also found that, while Asian tourists gave significantly lower ratings compared to western tourists, their facial expressions did not reflect their inner feelings.

Another study examining the tourists' after-travel behaviors related to the evaluation of hotel services was conducted by Tsang and Ap (2007). These authors compared the Asian and Western tourists' evaluations of the relational quality service provided by the guest contact employees of a hotel in Hong Kong. The findings of this study indicated that Asian tourists gave signifi- cantly lower ratings to the service quality compared to Western tourists. The authors explain these findings based on differences on the cultural dimension of power distance between Asian and Western tourists. Further, the authors also found that different factors were taken into consideration by Asian and Western tourists in their evaluations. The relevant considerations for the Western tourists included goal completion, efficiency and time savings, whereas for Asian tourists the quality of interpersonal relationship was the key consideration.

\section{ANALYSIS OF TOURIST BEHAVIORS: A CONCEPTUAL FRAMEWORK BASED ON HOFSTEDE'S CULTURAL DIMENSIONS}

The literature review discussed in the previous section is summarized on Table 2. For each of the 17 studies discussed in the literature review, the relevant tourist behavior(s) studied by the author(s) and Hofstede's (1980, 2001), five cultural dimensions used to explain the findings are identified on Table 2. Various tourist behaviors are identified with an index number indicated on Table-1: BT1 to BT14 for Before-Travel stage, DT1 to DT11 for During-Travel stage and AT1 to AT30 for After-Travel stage. The cultural dimensions used to explain the findings are listed under the applicable tourist behavior domains. The following key is used for listing the five cultural dimensions: $\mathrm{CD}=\mathrm{Confu}-$ cian Dynamism, $\mathrm{IC}=$ Individualism/Collectivism, $\mathrm{MF}=$ Masculinity/Femininity, $\mathrm{PD}=$ Power Distance and $\mathrm{UA}=$ Uncertainty Avoidance.

An examination of the summary given on Table 2 provides with some useful insights on the applicability of Hofstede's cultural dimensions to various tourist behavior domains. There is a very clear pattern in terms of which cultural dimensions are applicable on which stage of the tourist behavior. The behaviors in the after-travel stage include only three of the original four dimensions and the uncertainty avoidance dimension is missing in the studies of after-travel behaviors. Similarly, the power distance and masculinity/femininity dimensions are by and large missing for behaviors in the before and during stages. 
The analysis summarized on Table 2 shows that only individualism/collectivism and uncertainty avoidance dimensions are applicable in the before and during stages. We also note that the fifth dimension (Confucian Dynamism) is by and large missing, except in Wong and Lau (2001) study, as a part of the overall index of culture in Reisinger and Mavondo (2005) study, in formulating some propositions in Meng (2010) study and in the development of some measures in Kim and McKercher (2011) study. This can be attributed to a large extent to the fact that the Confucian Dynamism dimension has been discovered much later than the other four dimensions. We feel that the Confucian Dynamism dimension has a lot of potential for explaining several types of tourist behaviors, and we discuss some of these issues in the next section. In the meanwhile, our conceptual framework is based on the findings related to the original four dimensions of Hofstede (1980) as discussed in previous sections, and as summarized on Table 2.

Our conceptual framework is based on the insights drawn from our analysis of the applicability of Hofstede's cultural dimensions to various domains of travel behaviors and the processes underlying these applications. Based on these applicability patterns and our understanding of the underlying processes, we identify three categories of behaviors. These are labeled "Collectivity Orientation Driven Travel Behaviors," "Risk Tendencies Driven Travel Behaviors," and "Social Interaction Driven Travel Behaviors."

For the "Social Interaction Driven Travel Behavior" category, the three relevant cultural value dimensions are individualism/collectivism, power distance and masculinity/femininity. As previously discussed, these three dimensions together were earlier characterized by Hofstede and Bond (1988) as expected social behaviors capturing the behavior of individuals in different social situations: behavior towards groups, behavior towards juniors and seniors and behavior as a function of an individual's social gender roles respectively. It is indeed striking to note that tourist behaviors, which involve evaluations of their social encounters and experiences such as behaviors mostly in the after-travel category, stand out in terms of the application of these three cultural dimensions. The findings of the present study suggest that these three dimensions may exercise their influence either independently, in pairs or all three at the same time.

As regards the other two categories of behaviors, "Collectivity Orientation Driven Travel Behavior" and "Risk Tendencies Driven Travel Behaviors," another clear pattern was noted based on the results summarized on Table 2. For both before-travel and during-travel stages, the two dominant dimensions were individualism/collectivism and uncertainty avoidance. Further, for both stages of travel behaviors, these two dimensions acted independently as well as in conjunction with each other.

An in depth analysis of research done in this area, however, suggests that the underlying processes, through which the cultural influences work, are very different for before and during stages of travel behaviors. Many of the research studies discussed that tourists resort to measures such as group travel, traveling with a large party, etc., in order to reduce risk associated with traveling alone in a foreign country. Thus, risk reduction is the objective or motive that leads to a collectivistic action or outcome on part of many tourists in the during-travel stage. On the other hand, past research findings also indicate that many societies of the East, such as Japan and China, prefer to travel in groups due to the collectivistic nature of those societies. Thus, in these cultures collectivism is not an action or outcome of the risk reduction tendencies; it is an objective or motive in itself. The individuals in such collectivistic societies do receive the benefit of reduced risk associated with group travel; however, that is not the main or only reason why they travel in groups in the first place. Instead, collectivism is a preferred way of life to most Asian societies, an example being the concept of Japanese Travel Life Cycle discussed earlier. This distinction between the before and during stages of travel can be summed up as a sequential motive and outcome relationship. For the during-travel stage, risk reduction is the motive, which results in a collectivistic outcome $(\mathrm{UA} \rightarrow \mathrm{IC}$ ) whereas in the before-travel stage, 


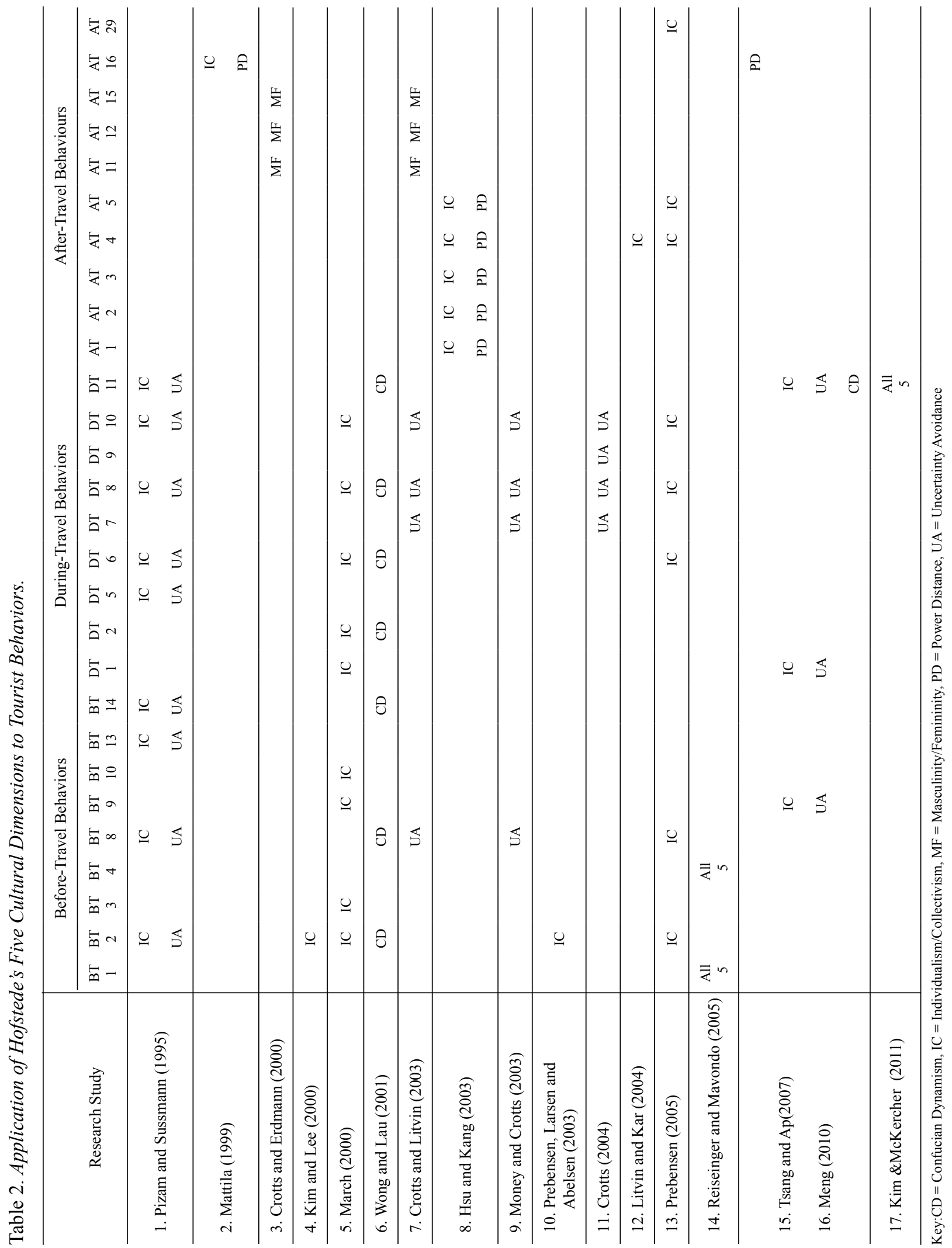


collectivism is the motive, which results in risk reduction as an outcome (IC $\rightarrow$ UA).

The conceptual framework developed in the current research is presented in Figure 1. This framework depicts the applicability of Hofstede's cultural dimensions to different categories of tourists' behaviors labeled "Collectivity Orientation Driven Travel Behaviors," "Risk Tendencies Driven Travel Behaviors," and "Social Interaction Driven Travel Behaviors". The conceptual framework also depicts the processes underlying the application of dominant values to these categories of travel behaviors.

\section{DISCUSSION}

We feel that the fifth cultural dimension, Confucian Dynamism, has great potential for application in the tourism research and studies of tourist behaviors, especially so in the after-travel category of behaviors, which we have characterized as "Social Interaction Driven Travel Behaviors." Travel and tourism is essentially an experiential product and, in a large proportion of these experiences, result from social interactions with tourism service providers. Tourist expectations are influenced by the norms and work ethics/philosophies applicable in their own cultures and the same are used for evaluating the experiences and services they received in a foreign culture. The Confucian Dynamism, which includes values relating to face, status, tradition, etc., are especially relevant for understating the behavior of Asian tourists. Some of the discrepancies in the research, discussed earlier in this paper, can be explained using concepts from this fifth dimension.

The study by Hsu and Kang (2003) contemplated that the Asian tourists' favorable response to the repeat visit intentions question, despite their unfavorable service evaluations, can be explained by the geographical proximity of Asian countries to Hong Kong. While the distance explanation certainly holds ground, we conjecture that the discrepancy in response to the service evaluation and repeat visit intention ques- tions can also be explained based on the Confucian Dynamism dimension. One of the values included in the Confucian Dynamism dimension is the concept of "face" which, along with other related cultural values of Chinese society such as "Harmony," "External Attribution," and "Continuity" (Mok \& DeFranco, 1999; Yau, 1988), is extremely relevant for understanding the behavior of tourists from China and other Asian countries, especially in the after-travel context.

The Asian tourist may be dissatisfied and may have evaluated their travel experience rather negatively, but when asked about their intention to revisit, they may provide a favorable response because such a response will be consistent with the notion of "continuity" in Chinese value system ${ }^{2}$. It would also protect the "face" of the service provider who may otherwise loose it if the tourist was to discontinue the association. Chinese people tend not to complain or take a public action; it would be considered an extreme behavior and against the Chinese value of "Harmony" with others. Often, "external attributions" are made to avoid confrontational situations. Indeed, the Confucian Dynamism concept can also explain why in Mattila's study the Asian tourists did not exhibit their feelings of dissatisfaction on their face, despite their unfavorable evaluation of the hotel service encounters. Complaining not only makes the service provider to loose his/her face, it is embarrassing for the tourist as well, which certainly is not desirable in many cultures of the world.

There are many salient implications of this research for travel and tourism marketing. The cultural values of Hofstede $(1980,1982,1983,2001)$ are found relevant for the understanding of tourist behaviors in all categories of the before, during, and after tourist experience. The influence of culture on tourist behavior spans from basic travel motivation to tourist decision making process involving preference and choice behaviors, and continues to various aspects of post-purchase behaviors such as service quality and perceived value evaluations, satisfaction and revisit

2 Chinese belief that once a relationship is established it is extremely difficult to break. 
intentions. Such insights enable the marketers to design effective strategies related to products and promotions geared toward different segments.

As discussed earlier, culture is the broadest determinant of human behavior and exerts a direct as well as an indirect (through social, personal, and psychological factors) influence on consumer behavior. Tourism is truly a complex global phenomenon and the influence of culture on behavior is especially salient in the field of tourism compared to other services. Hofstede's cultural dimensions are very widely acknowledged and referred in this context, and the current study expands our understanding of the applicability of these dimensions to various types of tourist behaviors and the underlying processes through which such influences work.

\section{FUTURE RESEARCH}

There is a wealth of research done in the field of travel and tourism that acknowledges the importance of culture and compares the behavior of tourists from different nationalities. However, the research studies that specifically use Hofstede's cultural dimensions as explanatory variables for their findings are rather limited. Therefore, there is ample scope for cross-cultural tourism research using theoretical frameworks such as those developed by Hofstede and his colleagues. Considering the complexity of culture and the complexity of the field of travel and tourism, it is not surprising therefore that the investigation of mechanisms and theoretical processes underlying the influence of culture on tourist behaviors has been relatively limited. We feel that there is an immense scope for developing in-depth theories of cross-cultural tourist behavior. Hofstede's cultural dimensions have proven an effective tool for understanding cultural differences in a variety of fields dealing with human behavior; certainly, the field of travel and tourism will benefit a great deal from further research related to the extension and applications of these cultural dimensions. The conceptual framework developed in our research provides with some further insights into the relative dominance of the various cultural dimensions in different stages of travel behaviors. The processes suggested here are, however, contemplative and there is room for further development and testing of these and other processes underlying the influence of various cultural dimensions on tourist behaviors. This suggests need for both conceptual and empirical research on this subject.

\section{References}

Beatty, S. E., Lynn, R. K., \& Pamela, H. (1991). Personal Values and Gift Giving Behaviors: A Study Across Cultures. Journal of Business Research, 22, 149157.

Bello, D., \& Etzel, M. (1985). The Role of Novelty in Pleasure Travel Experience. Journal of Travel Research, 40, 172-183.

Bond \& the Chinese Cultural Connection (1987). Chinese Values and the Search for Culture-free Dimensions of Culture. Journal of Cross-Cultural Psychology, 18(2), 143-164.

Bond, M. H., \& Lee, W.H. (1978). Face Saving in Chinese Culture: A Discussion and Experimental Study of Hong Kong Students. In M. H. Bond (Ed.) Social
Life and Development in Hong Kong. Hong Kong Chinese University Press.

Carr, N. (2001). An Exploratory Study of Gender Differences in Young Tourists' Perceptions of Danger within London. Tourism Management, 22, 565-570.

Chon, K. S. (1992). Self-image/Destination-image Congruity. Annals of Tourism Research, 19(2), 360-363.

Crotts, J. (2004). The Effect of Cultural Distance on Overseas Travel Behaviors. Journal of Travel Research, 43(August), 83-88.

Crotts, J. \& Erdmann, R. (2000). Does National Culture Influence Consumers' Evaluation of Travel Services? A Test of Hofstede's Model of Cross-cultural Differences. Managing Service Quality, 10(5), 410-419. 
Crotts, J. \& Litvin, S. W. (2003). Cross-cultural Research:Are Researchers Better Served by Knowing Tespondents' Country of Birth, Residence, or Citizenship? Journal of Travel Research, 42(November), 186-190.

De Mooij, M., \& Hofstede, G. (2011). Cross-cultural Consumer Behavior: A Review of Research Findings. Journal of International Consumer Marketing, 23(3/4), 181-192.

Hall, E. (1976). Beyond Cultures. New York: Doubleday, Anchor.

Han, B., \& Heather, J. (2001). Korean Tourists' Characteristics in Guam. Journal of Photo-Geographers, 11(1), 69-83.

Herkowitz, M. (1948). Man and His Work. New York: Knopf.

Hofstede, G. (1979). Value System in Forty Countries: Interpretation, Validation, and Consequences for Theory. In L. H. Eckensberger, W. J. Lonner, \& Y. H. Poortinga (Eds.) Cross-Cultural Contributions to Psychology. Lisse, The Netherlands: Swets and Zeitlinger.

Hofstede, G. (1980). Culture's Consequences: International Differences in Work-Related Values. Beverly Hills, CA: Sage.

Hofstede, G. (1982). Dimensions of National Cultures. In R. Rath, H. S. Asthana, D. Sinha, \& J. B. H. Sinha (Eds.) Diversity and Unity in Cross-Cultural Psychology. Lisse, The Netherlands: Swets and Zeitlinger.

Hofstede, G. (1983). Dimensions of National Cultures in Fifty Countries and Three Regions. In J. B. Deregowski, S. Dziurawiec, \& R. C. Annis (Eds.) Expectations in Cross-Cultural Psychology. Lisse, The Netherlands: Swets and Zeitlinger.

Hofstede, G. (1989). Organizing for Cultural Diversity. European Management Journal, 7(4), 390-397.

Hofstede, G. (2001). Culture's Consequences (2 ${ }^{\text {nd }}$ Ed.). Thousand Okas, CA: Sage Publications.

Hofstede, G. \& Bond, M. H. (1984). Hofstede's Culture Dimensions: An Independent Validation Using Rokeach's Value Survey. Journal of Cross-Cultural Psychology, 15(4), 417-433.
Hofstede, G. \& Bond, M. H. (1988). The Confucius Connection: From Cultural Roots to Economic Growth. Organizational Dynamics, 16(4), 5-21.

Hsu, C. H. C. \& Kang, S. K. (2003). Profiling Asian and Western Family Independent Travelers (FITs): An Exploratory Study. Asia Pacific Journal of Tourism Research, 8(1), 58-71.

Jafari, J. (1987). Tourism Models: The Socio-cultural Aspects. Tourism Management, 82(2), 151-159.

Jafari, J., \& Way, W. (1994). Multicultural Strategies in Tourism. Cornell Hotel \& Restaurant Administration Quarterly, 35(6), 72-29.

Kale, S., McIntyre, R., \& Weir, K. (1987). Marketing Overseas Tour Packages to the Youth Segments: An Empirical Analysis. Journal of Travel Research, 25(4), 20-31.

Kim, C., \& Lee, S. (2000). Understanding the Cultural Differences in Tourist Motivation between AngloAmerican and Japanese Tourists. Journal of Travel \& Tourism Marketing, 9(1/2), 153-170.

Kim, S. S., \& McKercher, B. (2011). The Collective Effect of National Culture and Tourist Culture on Tourist Behavior. Journal of Travel and Tourism Marketing, 28(2), 145-164.

Kluckhohn, C. (1954). Culture and Behavior. New York: Free Press.

Kogut, B., \& Singh, H. (1988). The Effect of National Culture on the Choice of Entry Mode. Journal of International Business Studies, 19(3), 411-432.

Kotler, P., \& Keller, K. L. (2009). Marketing Management (13 ${ }^{\text {th }}$ Ed.). Upper Saddle River, NJ: Prentice Hall.

Litvin, S. W., \& Kar, G. H. (2003). Individualism/ Collectivism as a Moderating Factor to the Selfimage Congruity Concept. Journal of Vacation Marketing, 10(1), 23-32.

Manrai, L. A., \& Manrai, A. K. (1996). Current Issues in the Cross-cultural and Cross-national Consumer Research. Journal of International Consumer Marketing, 8(3/4), 9-22.

Manrai, L. A., \& Manrai, A. K. (2011). Current Issues in the Cross-cultural and Cross-national Consumer 
Research in the Global Economy of the Twentyfirst Century. Journal of International Consumer Marketing, 23(3/4), 167-180.

March, R. (2000). The Japanese Travel Life Cycle. Journal of Travel \& Tourism Marketing, 9(1/2), 185-200.

Mattila, A. S. (1999). The Role of Culture and Purchase Motivation in Service Encounter Evaluations. The Journal of Services Marketing, 13(4/5), 376-389.

Meng, F. (2010). Individualism/Collectivism and Group Travel Behavior: A Cross-cultural Perspective. International Journal of Culture, Tourism, and Hospitality Research, 4(4), 340-351.

Mok, C., \& De Franco, A. L. (1999). Chinese Cultural Values: Their Implications for Traveland Tourism Marketing. Journal of Travel and Tourism Marketing, 8(2), 99-114.

Money, R., \& Crotts, J. (2003). The Effects of Uncertainty Avoidance on Information Search, Planning, and Purchases of International Travel Vacations. Tourism Management, 24(2), 191-202.

Moutinho, L. (1987). Consumer Behavior in Tourism. European Journal of Marketing, 21(109), 5-44.

Pizam, A., \& Sussmann, S. (1995). Does Nationality Affect Tourist Behavior? Annals of Tourism Research, 22(4), 901-917.

Plummer, J. T. (1977). Consumer Focus in Cross-national Research. Journal of Advertising, 6(1), 5-15.

Prebensen, N. K. (2005). Segmenting the Group Tourist Heading for Warmer Weather: A Norwegian Example. Journal of Travel \& Tourism Marketing, 19(4), 27-40.

Prebensen, N. K., Larsen, S., \& Abelsen, B. (2003). I'm not a typical Tourist: German Tourists' Self-perception, Activities, and Motivations. Journal of Travel Research, 41(May), 416-420.
Reisinger, Y., \& Mavondo, F. (2005). Travel Anxiety and Intentions to Travel Internationally: Implications of Travel Risk Perception. Journal of Travel Research, 43(February), 212-225.

Roehl, W., \& Fesenmaier, D. (1992). Risk Perceptions and Pleasure Travel: An Exploratory Analysis. Journal of Travel Research, 30(4), 17-26.

Sakakida, Y., Cole, S. T., \& Card, J. A. (2004). A Crosscultural Study of College Students' Travel Preferences: A Value-oriented Perspective. Journal of Travel \& Tourism Marketing, 16(1), 35-41.

Schiffman, L., \& Kanuk, L. (2007). Consumer Behavior ( $9^{\text {th }}$ Ed.). Upper Saddle River, NJ: Prentice Hall.

Seddighi, H. M., Nuttall, M., \& Theochaous, A. (2001). Does Cultural Background of Tourist Influence the Destination Choice? An Empirical Study with Special Reference to Political Instability. Tourism Management, 22, 181-191.

Triandis, H. C. (1994). Cultural and Social Behavior. New York: McGraw Hill.

Tsang, N. K., \& Ap, J. (2007). Tourists' Perceptions of Relational Quality Service Attributes: A Cross-cultural Study. Journal of Travel Research, 45(February), 355-363.

Watkins, H. S., \& Lin, R. (1996). Collectivism, Individualism $\&$ In-group Membership: Implications for Consumer Complaint Behavior in Multicultural Context. Journal of International Consumer Marketing, 8(3/4), 69-96.

Wong, S., \& Lau, E. (2001). Understanding the Behavior of Hong Kong Chinese Tourists on Group Tour Packages. Journal of Travel Research, 40(August), 57-67.

Yau, O. H. M. (1988). Chinese Cultural Values: Their Dimensions and Marketing Implications. European Journal of Marketing, 22(5), 44-57. 